\title{
Trans fatty acids in the Nordic countries
}

\author{
Antti Aro', Wulf Becker ${ }^{2}$ and Jan I. Pedersen ${ }^{3}$
}

'Department of Health and Functional Capacity, National Public Health Institute, Helsinki, Finland; ${ }^{2}$ Swedish National Food Administration, Uppsala, Sweden; ${ }^{3}$ Institute of Basic Medical Sciences, Department of Nutrition, University of Oslo, Oslo, Norway

Abstract

Trans fatty acids (TFA) comprise a variety of positional isomers, mainly with 18 carbon atoms and one double bond (C18:1). They are found in foods of ruminant animal origin and in partially hydrogenated vegetable oils. The isomeric composition of TFA in animal and vegetable foods differs, but no definite differences have been documented between the metabolic and health effects of the different isomers. In the Nordic countries the intake of TFA has declined during the past 10-15 years, mainly through reduced use of partially hydrogenated vegetable oils. TFA are mainly found in foods that contain far higher amounts of saturated fatty acids (SFA). The proportion of SFA plus TFA should be kept to one-third of total dietary fatty acids. The problem of excessive consumption of these unfavourable fatty acids should be managed with food-based dietary guidelines in agreement with the Nordic Nutrition Recommendations.

Keywords: food-based dietary guidelines; nutrition recommendations; ruminant fat; trans isomers; vegetable fat

\section{Introduction}

$\mathrm{I}$ someric trans fatty acids (TFA) are found in foods that contain ruminant animal fats or vegetable oils that have been partially hydrogenated for technological purposes. In both sources the quantitatively most important class of TFA is the cluster of isomers containing 18 carbon atoms and one double bond (C18:1). The position of the trans double bond varies between the $\Delta 4$ [CE1] and $\Delta 16$ carbon atoms of the fatty acid molecule, and the $\Delta 9-11$ isomers are the most common ones (1). Trans-vaccenic acid $(t-\Delta 11-18: 1)$ comprises about $30-50 \%$ of the trans $\mathrm{C} 18: 1$ isomers of ruminant animal fats, whereas in industrially hydrogenated fats elaidic acid $(t-\Delta 9-\mathrm{C} 18: 1)$ typically comprises $20-30 \%$ and $t-\Delta 10-\mathrm{C} 18: 1$ and $t-\Delta 11-\mathrm{C} 18: 1$ each contribute $10-20 \%$ of the $\mathrm{C} 18: 1$ isomers (2).

\section{Effects of different trans fatty acids}

In Dutch and Finnish studies that showed the lowdensity lipoprotein (LDL)-cholesterol-increasing and high-density lipoprotein (HDL)-cholesteroldecreasing effects of high doses of TFA, the TFA were produced by partial hydrogenation of higholeic acid sunflower oil (3-5). The product that contained high proportions of the $\Delta 6-9$ isomers has not been used in commercially available fats. Partially hydrogenated fish oils that contain high amounts of $\Delta 9$ elaidic acid and in addition long- chain C20-22 trans isomers showed particularly strong effects on serum lipoproteins in a Norwegian study (6), whereas partially hydrogenated soybean oil with preponderance of the $\Delta 10$ isomer showed weak and non-significant effects on HDL-cholesterol in some studies $(6,7)$. The $\Delta 11$ trans-vaccenic acid is to some extent desaturated in the human organism to conjugated linoleic acid (CLA) by $\Delta 9$ desaturase (8), but the health effects of this remain unknown. The effects on serum lipoproteins of trans-vaccenic acid have not been studied separately. Therefore, there may be some differences between the effects of different trans isomers, and additional studies on trans-vaccenic acid are needed (9). There was no significant difference in the effects of TFA of ruminant and vegetable origin on the risk of coronary heart disease (CHD) in the epidemiological studies when the intake levels were taken into account (10). Thus, on the basis of available evidence, all trans monoene fatty acids should be considered similar in their metabolic and health effects.

During partial hydrogenation TFA with more than one double bond are formed in small quantities. Such fatty acids may also be formed in nonhydrogenated vegetable oils due to heating of the oil during deodorization if special precautions are not taken (11). Even small amounts of these isomers have measurable unfavourable effects on blood 
lipids and lipoproteins with an increase in total cholesterol and the LDL-cholesterol:HDL-cholesterol ratio (12). Recently an observational study showed that high levels of trans-18:2 in red blood cell membranes, but not trans-18:1, were associated with increased risk of sudden cardiac death (13). It may therefore be prudent to pay more attention to this class of trans isomers.

\section{Trans fatty acids in foods and dietary intake}

Since the undesirable effects on lipoproteins of TFA were confirmed in 1990 (3), attempts were started in Europe to reduce TFA in processed foods. Improved technology allowed the production of soft margarines containing only small amounts of TFA or without TFA. In the European TRANSFAIR study conducted in 1995-1996 it was found that low-trans margarines had been produced generally without increasing the proportions of saturated fatty acids (SFA) in the products (14). The new margarines that were available in all 14 participating countries soon became market leaders. The tendency appears to be that since removal of TFA, palmitic acid has become a dominating SFA in margarines (15). Considering the potent hypercholesterolaemic effect of palmitic acid a better alternative would be to replace at least part of the TFA with stearic acid.

In the TRANSFAIR study high amounts of TFA were found in certain industrial fats and processed foods such as potato chips, fatty pastries, biscuits, wafers and soup powders. The average contribution to total fat intake by TFA ranged from $0.5 \%$ of the energy intake $(E \%)$ in some Mediterranean countries to $2.1 E^{\%}$ in Iceland (16), which corresponds to about 1.5 and $7 \mathrm{~g}$ per day, respectively, at an energy intake of around $12 \mathrm{MJ} / \mathrm{d}$. During the past 10 years the amounts of TFA derived from partially hydrogenated vegetable oils have been reduced in processed foods in the Nordic countries, but systematic studies of representative food samples have not been repeated since the TRANSFAIR study. In Norway the average intake of TFA was about $4 E^{\%} \%$ in 1958 (17) but it had declined to $1.5 E \%$ already in 1996 . During the past 10 years the average intakes of TFA have been reduced further to $0.6 E \%$ in Norway (18) and from 0.8 to $0.5 E \%$ in Finland (19), apparently by reduced consumption of partially hydrogenated vegetable fats. In Sweden recent data show an average TFA intake of $0.9 \mathrm{E} \%$ among children, of which about half originates from ruminant fat and half presumably from partially hydrogenated vegetable fats (20).

The desired texture in Danish pastries, croissants and wafers, and the stability of fats used for biscuits or for repeated deep-frying are not achieved with unsaturated vegetable oils. Therefore, when partially hydrogenated vegetable fats are replaced in processed foods, fats such as coconut oil and other palm kernel oils containing high amounts of SFA and low in polyunsaturated fatty acids (PUFA) are commonly used. The present tendency to reduce TFA in industrial fats may lead to products that are higher in SFA and contain less unsaturated fatty acids than the previously available products. In Finland sweet biscuits that had been marketed after the year 2000 were found to contain no TFA, but most brands were high in SFA and low in cisunsaturates, indicating the use of coconut oil. Similar trends have been observed for foods such as sweet bakery products on the Swedish market (21).

In a recent study a genetically modified (GM) plant oil that contained relatively small proportions of both SFA and PUFA had favourable effects on serum lipoproteins compared with partially hydrogenated vegetable oil (22). Novel GM oils may offer advantages for food production in the future, if their use becomes accepted in Europe.

\section{Dietary guidelines}

In the food-based dietary guidelines people will be advised to limit their consumption of high-fat processed foods, because their fatty acid composition is generally unfavourable irrespective of their TFA content. The fatty acid composition of dairy products and beef remain unchanged, but the TFA intake from processed foods is declining. In the Nordic countries, possibly with the exception of Iceland, the present average intake of TFA is between 0.5 and $1.0 \mathrm{E} \%$, corresponding to about $1.5-3 \mathrm{~g}$ per day, and today the major part is derived from ruminant animal fats.

TFA are mainly found in foods that are also the main sources of SFA. TFA are a minor dietary component, but the foods that contain these fatty acids affect the balance between the favourable (cisMUFA plus cis-PUFA) and unfavourable (SFA plus TFA) fats in the diet. According to the Nordic Nutrition Recommendations for 2004, the intake of MUFA plus PUFA should account for two-thirds and that of SFA plus TFA for a maximum of 
one-third ( $\sim 10 E \%)$ of the total dietary fat intake (23). Based on epidemiological cohort studies, Oomen et al. (24) estimated that a reduction in TFA intake by $2 E \%$ would reduce the risk of CHD by $25 \%$. The effect that could be achieved in the Nordic countries would be about one-tenth of this. The recommended goal of $10 \mathrm{E} \%$ provided by dietary SFA plus TFA would require a reduction by one-third in the intakes of these fatty acids (23). Reduction in the consumption of SFA by $5 E \%$ could reduce the risk of CHD by about $30 \%$, assuming that SFA are replaced partly by MUFA and PUFA, and partly by carbohydrates (25). A corresponding decrease by $0.2-0.3 E \%$ in TFA intake would have a small additional effect $(\sim 3 \%)$ on the risk of CHD.

In the Nordic countries self-regulation by industry has resulted in markedly reduced intakes of TFA from partially hydrogenated vegetable oils. The problem of excessive consumption of the unfavourable fatty acids (SFA and TFA) should be managed by food-based dietary guidelines in agreement with the Nordic Nutrition Recommendations.

\section{References}

1. Aro A, Kosmeijer-Schuil $\mathrm{T}$, van de Bovenkamp $\mathrm{P}$, Hulshof P, Zock P, Katan MB. Analysis of the $C_{18: 1}$ cis and trans fatty acid isomers by the combination of gas-liquid chromatography of 4,4-dimethyloxazoline derivatives and methyl esters. JAOCS 1998; 75: 977-85.

2. Opinion of the Scientific Panel on Dietetic Products, Nutrition and Allergies on a request from the Commission related to the presence of trans fatty acids in foods and the effect on human health of the consumption of trans fatty acids (adopted on 8 July 2004). EFSA Journal 2004; 81: 1-49. http://www.efsa.eu.int/science/ nda/nda_opinions/588/opinion_nda09_ej81_tfa_en1.pdf

3. Mensink RP, Katan MB. Effect of dietary trans fatty acids on high-density and low-density lipoprotein cholesterol levels in healthy subjects. N Engl J Med 1990; 323: 439-45.

4. Zock PL, Katan MB. Hydrogenation alternatives: effects of trans fatty acids and stearic acid versus linoleic acid on serum lipids and lipoproteins in humans. J Lipid Res 1992; 33: 399-410.

5. Aro A, Jauhiainen M, Partanen R, Salminen I, Mutanen M. Stearic acid, trans fatty acids, and dairy fat: effects on serum and lipoprotein lipids, apolipoproteins, lipoprotein(a), and lipid transfer proteins in healthy subjects. Am J Clin Nutr 1997; 65: 1419-26.

6. Almendingen K, Jordal O, Kierulf P, Sandstad B, Pedersen JI. Effects of hydrogenated fish oil, partially hydrogenated soybean oil, and butter on serum lipoproteins and Lp[a] in men. J Lipid Res 1995; 36: 1370-84.
7. Mauger J-F, Lichtenstein AH, Ausman LM, Jalbert SM, Jauhiainen M, Ehnholm C, et al. Effect of different forms of dietary hydrogenated fats on LDL particle size. Am J Clin Nutr 2003; 78: 370-5.

8. Turpeinen AM, Mutanen M, Aro A, Salminen I, Basu S, Palmquist DL, et al. Bioconversion of vaccenic acid to conjugated linoleic acid in humans. Am J Clin Nutr 2002; 76: 504-10.

9. Aro A. Complexity of issue of dietary trans fatty acids. Lancet 2001; 357: 732-3.

10. Weggemans RM, Rudrum M, Trautwein EA. Intake of ruminant versus industrial trans-fatty acids and risk of coronary heart disease: what is the evidence? Eur J Lipid Sci Technol 2004; 106: 390-7.

11. Pedersen JI. More on trans fatty acids. Br J Nutr 2001; 85: 249-50.

12. Vermunt SH, Beaufrere B, Riemersma RA, Sebedio JL, Chardigny JM, Mensink RP, TransLinE Investigators.. Dietary trans alpha-linolenic acid from deodorised rapeseed oil and plasma lipids and lipoproteins in healthy men: the TransLinE Study. Br J Nutr 2001; 85: 387-92.

13. Lemaitre RN, King IB, Mozaffarian D, Sootodehnia N, Siscovick DS. Trans-fatty acids and sudden cardiac death. Atheroscler Suppl 2006; 7: 13-5.

14. Aro A, Van Amelsvoort J, Becker W, van Erp-Baart MA, Kafatos A, Leth T, et al. Trans fatty acids in dietary fats and oils from 14 European countries. The TRANSFAIR study. J Food Composit Anal 1998; 11: 137-49.

15. Pedersen JI. Composition of "post trans" margarines (abstract). Fats and health - update on dietary phytosterols, trans-fatty acids and conjugated linoleic acids. DGF meeting, 19-20 October 2006, Frankfurt, Germany.

16. Hulshof KFAM, van Erp-Baart MA, Anttolainen M, Becker W, Church SM, Couet C, et al. Intake of fatty acids in Western Europe with emphasis on trans fatty acids: the TRANSFAIR study. Eur J Clin Nutr 1999; 53: $143-57$.

17. Johansson L, Rimestad AH, Andersen LF. [Trans fatty acids in the Norwegian diet]. Scand J Nutr 1994;38:626. (In Norwegian with English summary.)

18. Johansson L, Borgejordet A, Pedersen JI. [Trans fatty acids in the Norwegian diet]. Tidsskr Nor Laegeforen 2006; 126: 760-3. (In Norwegian with English summary at www.tidsskriftet.no)

19. Männistö S, Ovaskainen M-L, Valsta L. The national FINDIET 2002 study. Publications of the National Public Health Institute B3/2003. Helsinki; 2003.

20. Enghardt Barbieri H, Pearson M, Becker W. [Dietary habits and nutrient intake in Swedish 4-year-old children and schoolchildren in grade 2 and 5. Riksmaten children 2003]. Uppsala: Livsmedelsverket; 2006. (In Swedish with English summary.)

21. Torelm I. [More sugar - less trans fatty acids in sweet bakery products]. Vår Föda 2004; 56: 26-7. (In Swedish.)

22. Lichtenstein AH, Matthan NR, Jalbert SM, Resteghini NA, Schaefer EJ, Ausman LM. Novel soybean oils with different fatty acid profiles alter cardiovascular disease 
risk factors in moderately hyperlipidemic subjects. Am J Clin Nutr 2006; 84: 497-504.

23. Nordic Nutrition Recommendations 2004 - integrating nutrition and physical activity. Nordic Council of Ministers, Copenhagen. Nord 2004; 13: 1-436.

24. Oomen CM, Ocké MC, Feskens EJM, van Erp-Baart MA, Kok FJ, Kromhout D. Association between trans fatty acid intake and 10-year risk of coronary heart disease in the Zutphen Elderly Study: a prospective population-based study. Lancet 2001; 357: 746-51.

25. Hu FB, Stampfer MJ, Manson JE, Rimm E, Colditz GA, Rosner BA, et al. Dietary fat intake and the risk of coronary heart disease in women. N Engl J Med 1997; 337: 1491-9.

\section{Antti Aro}

National Public Health Institute (TTO/MALA)

Mannerheimintie I66, Fl-00300 Helsinki

Finland.

Tel: +35850 53237|6,

E-mail: antti.aro@ktl.fi 